\title{
Crop yields and soil organic carbon dynamics in a long-term fertilization experiment in an extremely arid region of northern Xinjiang, China
}

\author{
LYU Jinling ${ }^{1,2,3}$, LIU Hua ${ }^{4}$, WANG Xihe ${ }^{4}$, Rodrigo OLAVE ${ }^{5}$, TIAN Changyan ${ }^{1}$, LIU \\ Xuejun $^{6 *}$ \\ ${ }^{1}$ State Key Laboratory of Desert and Oasis Ecology, Xinjiang Institute of Ecology and Geography, Chinese Academy of Sciences, \\ Urumqi 830011, China; \\ ${ }^{2}$ Graduate University of Chinese Academy of Sciences, Beijing 100049, China; \\ ${ }^{3}$ Institute of Plant Nutrition, Resources and Environmental Sciences, Henan Academy of Agricultural Sciences, Zhengzhou \\ 450000, China; \\ ${ }^{4}$ Institute of Soils and Fertilizers, Xinjiang Academy of Agricultural Sciences, Urumqi 830000, China; \\ ${ }^{5}$ Agri-Food and Biosciences Institute, Hillsborough, BT26 6DR, United Kingdom; \\ ${ }^{6}$ College of Resources and Environmental Sciences, China Agricultural University, Beijing 100193, China
}

\begin{abstract}
A long-term fertilization experiment was set up in northern Xinjiang, China to evaluate the dynamics of crop production and soil organic carbon (SOC) from 1990 to 2012 with seven fertilization treatments. The seven treatments included an unfertilized control (CK) and six different combinations of phosphorus (P), potassium $(\mathrm{K})$, nitrogen $(\mathrm{N})$, straw $(\mathrm{S})$ and animal manure $(\mathrm{M})$. The balanced fertilization treatments had significantly $(P<0.05)$ higher average yields than the unbalanced ones. The treatment with $2 / 3 \mathrm{~N}$ from potassium sulfate (NPK) and $1 / 3 \mathrm{~N}$ from farmyard manure (NPKM) had a higher average yield than the other treatments. The average yields (over the 23 years) in the treatments of NPK, and urea, calcium superphosphate (NP) did not differ significantly $(P>0.05)$ but were higher than that in the treatment with urea and potassium sulfate $(\mathrm{NK} ; P<0.05)$. The results also show that the highest increases in SOC $(P<0.05)$ occurred in NPKM with a potential increase of $1.2 \mathrm{t} \mathrm{C} /\left(\mathrm{hm}^{2} \cdot a\right)$. The increase in SOC was only $0.31,0.30$ and $0.12 \mathrm{t} \mathrm{C} /\left(\mathrm{hm}^{2} \cdot \mathrm{a}\right)$ for NPKS $(9 / 10 \mathrm{~N}$ from NPK and 1/10 N from straw), NPK and NP, respectively; and the SOC in the NP, NK and CK treatments were approaching equilibrium and so did not rise or fall significantly over the 23-year experiment. A complete NPK plus manure fertilization program is recommended for this extremely arid region to maximize both yields and carbon sequestration.
\end{abstract}

Keywords: long-term fertilization experiment; extremely arid conditions; soil organic carbon; organic C inputs; Xinjiang

Citation: LYU Jinling, LIU Hua, WANG Xihe, Rodrigo OLAVE, TIAN Changyan, LIU Xuejun. 2017. Crop yields and soil organic carbon dynamics in a long-term fertilization experiment in an extremely arid region of northern Xinjiang, China. Journal of Arid Land, 9(3): 345-354. doi: 10.1007/s40333-017-0097-0

\section{Introduction}

Increasing crop yield and also improving soil organic carbon (SOC) sequestration in farmland are anticipated requirements for sustainable agriculture (Kismányoky and Tóth, 2013). In recent years, with increasing concern about high concentrations of atmospheric $\mathrm{CO}_{2}$ and the potential role for carbon sequestration in croplands, increasingly more regional field experiments have been carried out in croplands. The results from these experiments form the basis of the development of options for increasing crop yield and sequestrating SOC ( $\mathrm{Li}$ et al., 2005; Cai and

*Corresponding author: LIU Xuejun (E-mail: liu310@cau.edu.cn)

Received 2016-05-31; revised 2017-04-08; accepted 2017-04-13

CC Xinjiang Institute of Ecology and Geography, Chinese Academy of Sciences, Science Pressand Springer-VerlagBerlin Heidelberg 2017 
Qin et al., 2006). However, crop yield and SOC sequestration may differ under the complicated situations involving different combinations of soil types, environmental conditions and farming methods (Ai et al., 2017). For example, the long-term cropping experiment of northeastern China showed that the SOC content under the chemical fertilizer treatment decreased significantly with the increase in planting period, while the SOC in grey desert soil of northwestern China showed a significant increase trend of SOC content with the increase in planting period (Xu and Liu, 2006). In addition, there have been several reports suggesting that soil fertility and crop yield declined with continuous application of inorganic fertilizers without organic inputs (Min et al., 2011). On the other hand, numerous studies have shown that balanced application of inorganic fertilizers can maintain soil fertility and can slightly increase SOC content (Bremer et al., 1992; Bao et al., 2000; Cai and Qin, 2006). Therefore, the relationships among the crop yield, yield stability and SOC input and output are rather complex in different areas, and it is thus necessary to explore the relationships under different environmental conditions and farmland management practices to search for the treatments that can achieve the optimal crop yield with the maximal SOC sequestration. In China, most of the crop yield- and SOC-related studies have focused on areas with intensively managed agriculture, such as the North China Plain, the Loess Plateau, and the South China. But, much less attention has been paid to the extremely arid areas of northwestern China (Manna et al., 2007; Niu et al., 2011; Wang et al., 2011; Guo et al., 2012). So there is a need to select typical soil types located in extremely arid areas as objects of study to quantify the crop yields and the relations with SOC.

The grey desert soil is one of the most typical arid desert oasis soil types in northwestern China, where the diurnal temperature differences are large and the annual evaporations are high with soil wetting and drying cycles being frequent and soil freezing and thawing being dramatic (Luo et al., 2006; Xu and Liu, 2006). Studies showed that SOC is easily affected by environmental factors in this area. For example, wet and dry cycles in the soil or freezing-thaw alternations can accelerate the SOC mineralization (Yang et al., 2011; Rong et al., 2012; Lv et al., 2014). Besides, the croplands in the extremely arid environment have less SOC input in comparison with those in other ecosystems. In the conversion process of desert soil into cropland soil, the litter, plant roots and root exudates were reported to have significantly increased (Rong et al., 2012).

In this study, we used a long-term experiment to evaluate the effects of different fertilizer treatments on the yields of maize (Zea mays L.), winter or spring wheat (Triticum aestivum L.) and cotton (Gossypium hirsutum L.), and to quantify the long-term SOC dynamics under different fertilization practices and to estimate carbon sequestration under different fertilizer treatments in an extremely arid region.

\section{Materials and methods}

\subsection{Experimental site}

The experimental site is located at Anningqu near Urumqi $\left(43^{\circ} 57^{\prime} 43^{\prime \prime} \mathrm{N}, 87^{\circ} 30^{\prime} 05^{\prime \prime} \mathrm{E}\right.$; Fig. 1), the capital city of Xinjiang Uygur Autonomous Region in northwestern China. Previously the site was a wasteland where the fertile soil remained in its original conditions before the long-term experiment started in 1989. The mean annual precipitation and evaporation are approximately 223 and $2000 \mathrm{~mm}$, respectively. The annual mean temperature is $7.7^{\circ} \mathrm{C}$ (Fig. 2) with an annual sunshine hours of $2594 \mathrm{~d}$. The annual frost-free period is about $156 \mathrm{~d}$ (Liu et al., 2010). The top layer $(20 \mathrm{~cm})$ of the soil consists of clay, silt and sand fractions, accounted for $30.3 \%, 52.5 \%$ and $17.2 \%$, respectively (Yang et al., 2012). The soil was classified as grey desert soil according to the American soil taxonomy (Gong et al., 2007). In 1989, the top $20 \mathrm{~cm}$ of the soil profile had a SOC content of $15.2 \mathrm{~g} / \mathrm{kg}$, total nitrogen $(\mathrm{N})$ of $0.868 \mathrm{~g} / \mathrm{kg}$, total phosphorus $(\mathrm{P})$ of $0.667 \mathrm{~g} / \mathrm{kg}$, total potassium (K) of $23 \mathrm{~g} / \mathrm{kg}$, available $\mathrm{P}$ (Olsen-P) of $3.4 \mathrm{mg} / \mathrm{kg}$ and available K of $288 \mathrm{mg} / \mathrm{kg}$. The $\mathrm{pH}$ value was 8.1. The experiment consisted of 7 fertilization treatments (Table 1) as no fertilizer (CK), phosphorus and potassium (PK), urea and calcium superphosphate (NP), urea and 
potassium sulfate (NK), urea, calcium superphosphate and potassium sulfate (NPK), 2/3 N from NPK and 1/3 $\mathrm{N}$ from farmyard manure (NPKM), and 9/10 $\mathrm{N}$ from NPK and 1/10 N from straw (NPKS).

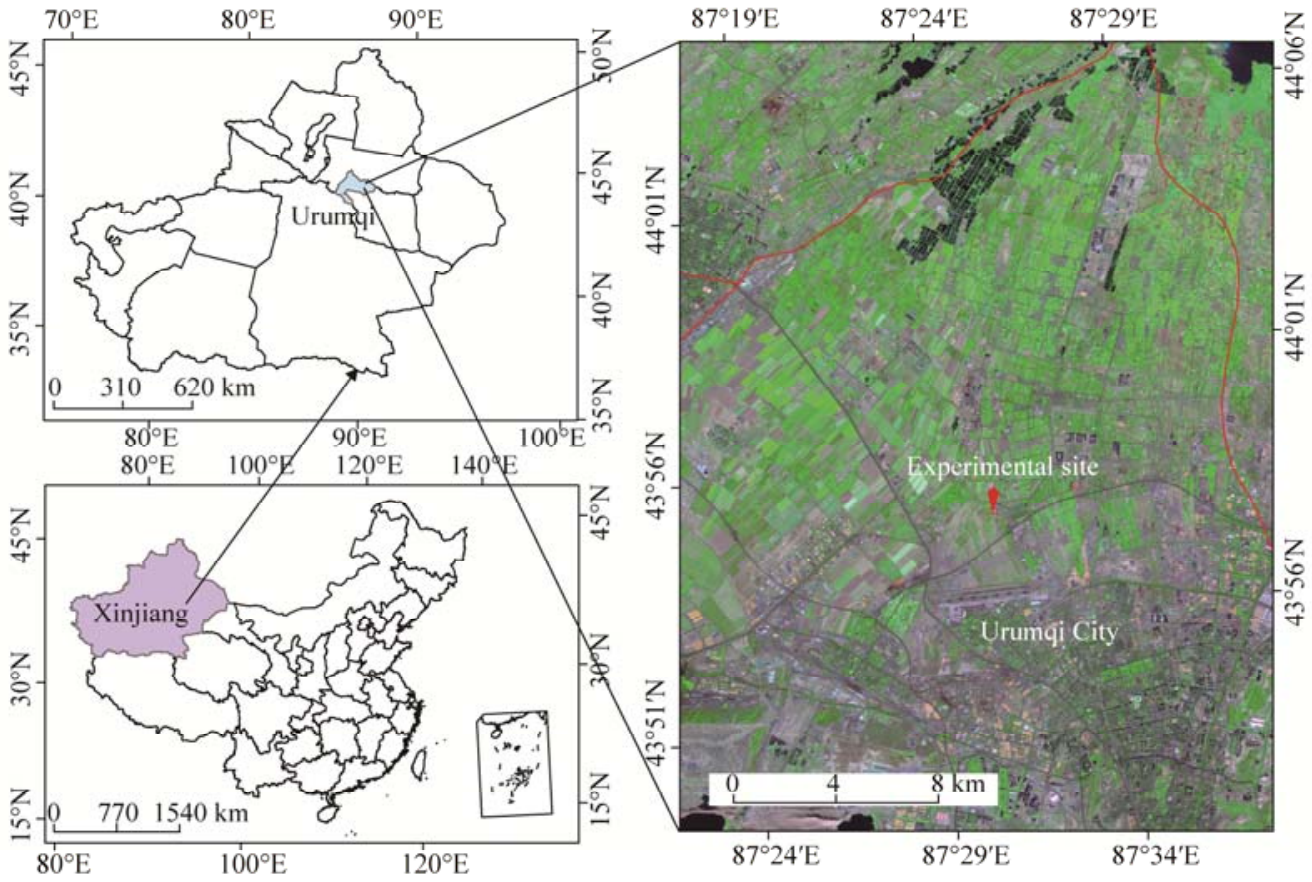

Fig. 1 Location of the long-term experimental site
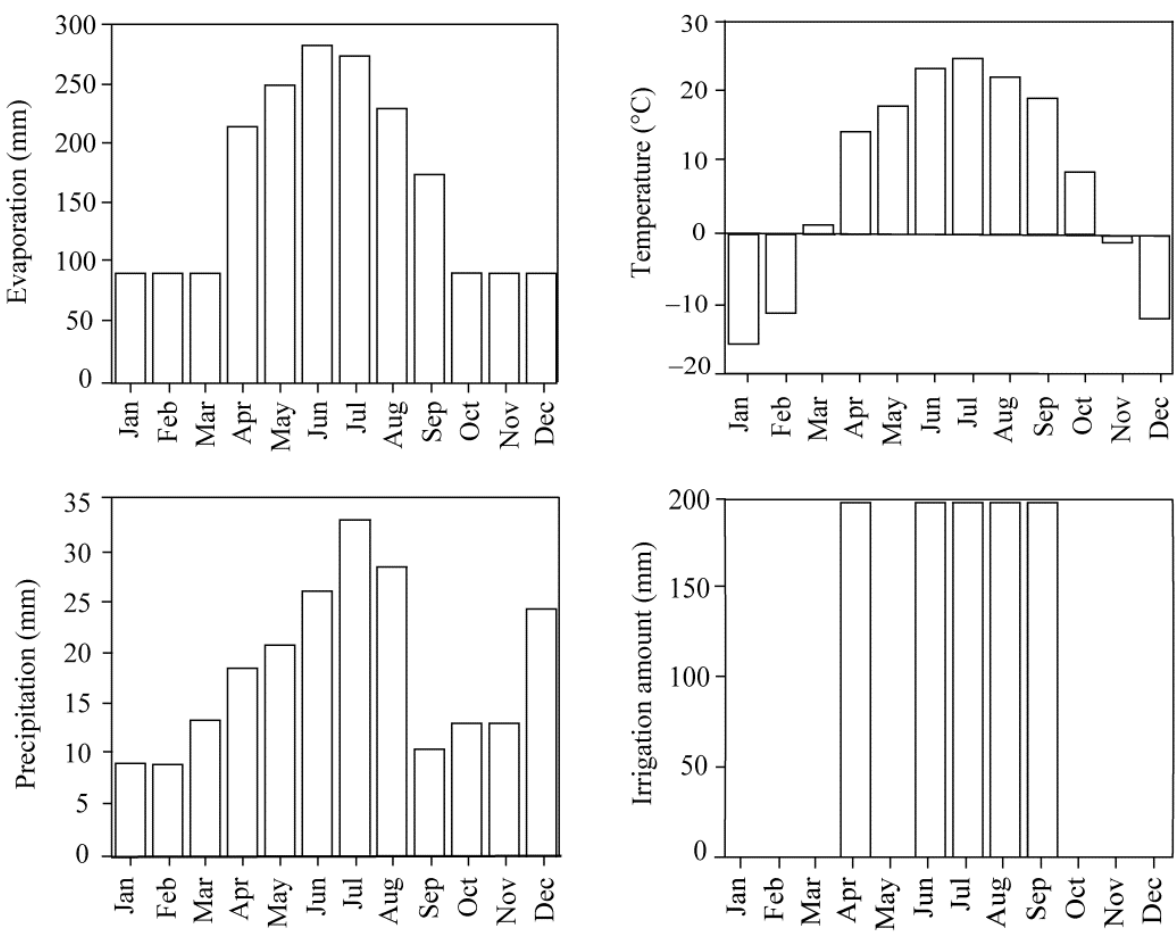

Fig. 2 Mean monthly evaporation, temperature, precipitation and irrigation from 1990 to 2012 at the experimental site 
Table 1 Amounts of fertilizer applied under different fertilizer treatments at the experimental site

\begin{tabular}{|c|c|c|c|c|c|}
\hline \multirow{3}{*}{ Treatment } & \multicolumn{3}{|c|}{$\mathrm{N}$ fertilizer } & \multirow{3}{*}{$\begin{array}{c}\text { P fertilizer } \\
\text { Total } \\
\left(\mathrm{kg} \mathrm{P}_{2} \mathrm{O}_{5} / \mathrm{hm}^{2}\right)\end{array}$} & \multirow{3}{*}{$\begin{array}{c}\text { K fertilizer } \\
\text { Total } \\
\left(\mathrm{kg} \mathrm{K}_{2} \mathrm{O} / \mathrm{hm}^{2}\right)\end{array}$} \\
\hline & Basal & Topdressing & Total & & \\
\hline & \multicolumn{3}{|c|}{$\left(\mathrm{kg} \mathrm{N} / \mathrm{hm}^{2}\right)$} & & \\
\hline CK & 0 & 0 & 0 & 0 & 0.0 \\
\hline PK & 0 & 0 & 0 & 138 & 58.5 \\
\hline NK & 144 & 96 & 240 & 0 & 58.5 \\
\hline NP & 144 & 96 & 240 & 138 & 0.0 \\
\hline NPK & 144 & 96 & 240 & 138 & 58.5 \\
\hline NPKS & 163 & 77 & 240 & 138 & 58.5 \\
\hline NPKM & 192 & 48 & 240 & 138 & 58.5 \\
\hline
\end{tabular}

Note: P, phosphorus; K, potassium; N, nitrogen; CK, no fertilizer; PK, phosphate and potassium; NK urea and potassium sulfate; NP, urea and calcium superphosphate; NPK; urea, calcium superphosphate and potassium sulfate; NPKM, $2 / 3 \mathrm{~N}$ from NPK and 1/3 N from farmyard manure; NPKS, 9/10 N from NPK and 1/10 N from straw. $\mathrm{N}$ fertilizer was sourced from chemical, straw, and manure.

\subsection{Field experiment}

As a long-term positioning experiment lasted for more than 20 years, the experiment of this study adopted a seasonal or annual crop rotation pattern. For example, maize, spring wheat, and winter wheat were planted in 1990, 1991 and 1992, respectively, and maize was planted again in 1993 to start the next round. Cotton was planted three times over the study period in 1999, 2009, and 2012. We conducted the analysis based on the crops planted in each year.

Nitrogen was applied in two split dressings with $60 \% \mathrm{~N}$ as the basal fertilizers and $40 \% \mathrm{~N}$ as the topdressing in the NPK, NPKM, NK, N and NP treatments, while P, K, and organic fertilizers were applied as basal fertilizers. The organic fertilizer was derived from sheep manure. Among the treatments, the NPKM treatment had one additional application of farmyard manure (30 $\left.\mathrm{t} /\left(\mathrm{hm}^{2} \cdot \mathrm{a}\right)\right)$, which contained $2.9 \mathrm{t} \mathrm{C} /\left(\mathrm{hm}^{2} \cdot \mathrm{a}\right)$ and $160 \mathrm{~kg}$ organic $\mathrm{N} /\left(\mathrm{hm}^{2} \cdot \mathrm{a}\right)$. The amount of straw for NPKS treatment was approximately $6 \mathrm{t} /\left(\mathrm{hm}^{2} \cdot \mathrm{a}\right)$ which contained $1.5 \mathrm{t} \mathrm{C} /\left(\mathrm{hm}^{2} \cdot \mathrm{a}\right)$ and $24 \mathrm{~kg}$ organic $\mathrm{N} /\left(\mathrm{hm}^{2} \cdot \mathrm{a}\right)$.

The experimental plots were $466.5 \mathrm{~m}^{2}$ each and separated by concrete banks, which were 70 $\mathrm{cm}$ in depth with $10 \mathrm{~cm}$ above the soil surface to prevent leaching. Each treatment had three plots as replicates. Spring wheat was sown in late April and harvested in August while winter wheat was sown in October and harvested in early June of the following year. Maize and cotton were sown in late April and harvested in September and October respectively. The field was irrigated 4-5 times during the wheat-growing season, 4-5 times in the maize-growing season and 10-15 times in the cotton-growing season, normally depending upon the times and the precipitation. The volume of water used for irrigation was approximately $2850-6000 \mathrm{~m}^{3} /\left(\mathrm{hm}^{2} \cdot \mathrm{a}\right)$ with an annual frequency of 5-12 times. Herbicides and pesticides were applied to control weed growth and insect infestation. The stubble and roots of wheat and maize were left in the fields after the harvest. The straws were removed from the field except for the NPKS treatment. Grain and straw were air dried and weighed separately.

\subsection{Sampling and SOC determination}

Soil samples from the three replicates were collected after each harvest since 1990. We randomly sampled at six points in each plot and mixed thoroughly to get one representative sample per plot. The soil samples were air-dried, crushed through a 2-mm sieve and stored in sealed plastic jars for further analysis. SOC contents were immediately determined in the laboratory after collection using external heating $\left(170^{\circ} \mathrm{C}-180^{\circ} \mathrm{C}\right.$ for $\left.5 \mathrm{~min}\right)$ and oil baths (Bao, 2000). Bulk density was determined using the cutting ring method in 2009. We did not measure the temporal change in bulk density because the change was assumed to be negligible for this study. The soil particle size composition was analyzed using the pipette method (Batjes, 1996).

\subsection{Data analysis}

Statistical analysis was performed using the SPSS 16.0 package. Prior to statistical analysis, data 
were examined for homogeneity of variance. Averages from the treatments were compared against each other using Fisher's least significant difference at a probability level of 0.05 . Comparisons of treatment effects on SOC pools were analyzed using the one-way ANOVA.

\section{Results}

\subsection{Grain yield dynamics}

Yield dynamics of spring wheat, winter wheat and maize are shown in Figure 3. Table 2 presented the average yields of each crop over the 23 -year period, coefficients of variation among years, and the crop yield differences from NPKM (which was taken as the baseline for the treatments). The results showed that the NPKM treatment had higher yields for spring wheat $\left(4.2 \mathrm{t} / \mathrm{hm}^{2}\right)$, winter wheat $\left(5.7 \mathrm{t} / \mathrm{hm}^{2}\right)$, maize $\left(8.2 \mathrm{t} / \mathrm{hm}^{2}\right)$ and cotton $\left(3.8 \mathrm{t} / \mathrm{hm}^{2}\right)$ than those under the other treatments, except for the NPKS and NPK. Spring and winter wheat yields under NPK, NP and NPKS treatments were not significantly different $(P>0.05)$. But NPKS treatment had higher yields for maize and cotton than NPK and NP $(P<0.05)$ treatments. The yields of all crops under PK, NK and CK treatments were significantly $(P<0.01)$ lower than those under the balanced fertilizer treatment. As the soil was originally extremely deficient in $\mathrm{P}$, spring wheat, winter wheat, maize and cotton yields were low under NK and CK treatments, and the yield differences between NK and $\mathrm{CK}$ treatments were not significantly different $(P>0.05)$. The yields under PK and NK treatments had no significant difference $(P>0.05)$ in spring wheat, winter wheat, maize and cotton. The NPK treatment had significantly $(P<0.01)$ higher yield than PK and NK treatments, suggesting that the grey soil was extremely low in $\mathrm{N}$ and $\mathrm{P}$. Instead, the yields of spring wheat, winter wheat, maize and cotton under NP and NPK treatments showed no significant difference $(P>0.05)$, indicating that the grey soil was high in $\mathrm{K}$ content. Over the 23 -year experiment, the yields of all the crops presented significantly decreasing trends under the PK, NK and CK treatments, but increasing trends under NPKM, NPK and NP treatments were observed (Fig. 3).

The largest annual variation in crop yield was observed in the control plots and the second largest annual variation was in the PK-treatment plots. The coefficients of variation of NPKM, NPK, NP and NPKS treatments for winter wheat were $20.4 \%, 23.9 \%, 23.8 \%$ and $35.5 \%$,
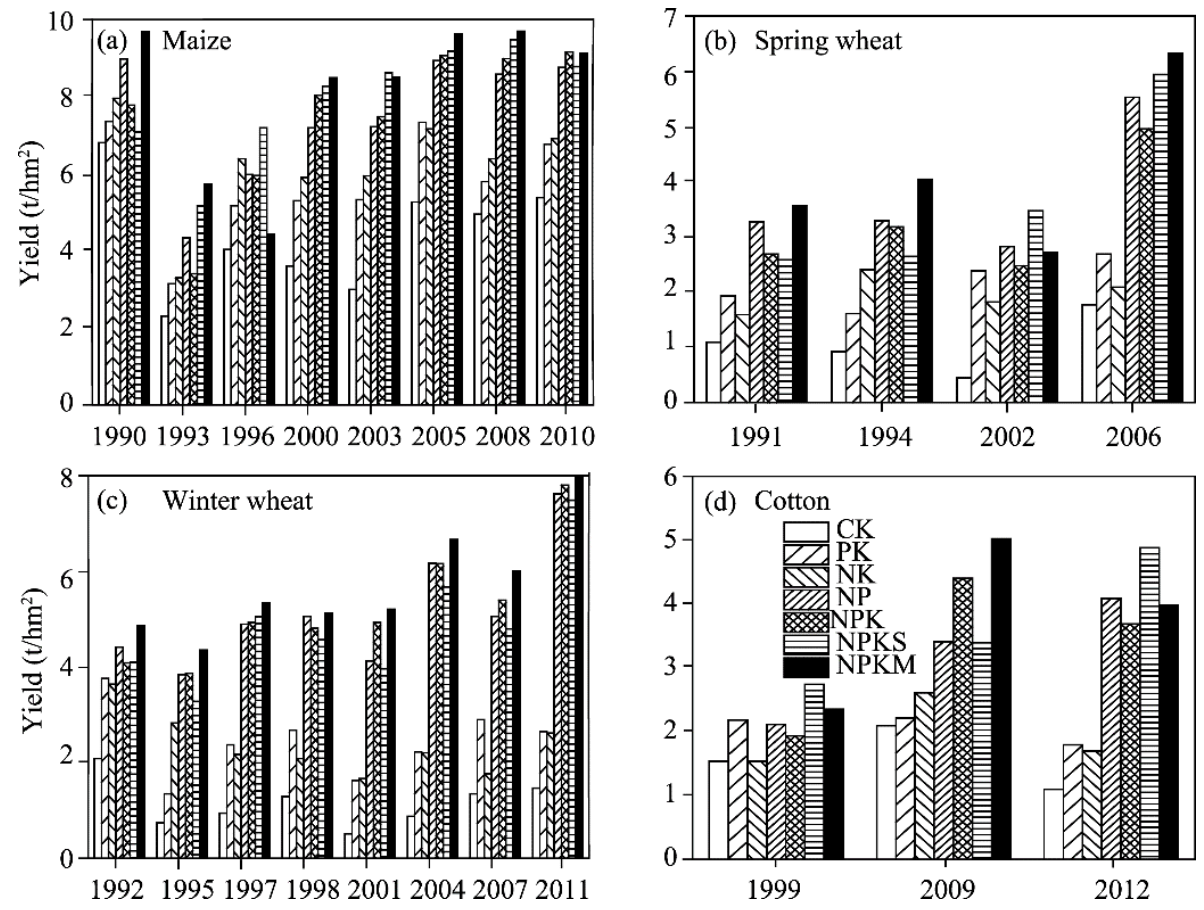

Fig. 3 Yield dynamics of maize (a), spring wheat (b), winter wheat (c), and cotton (d) over the study period 
respectively, and the coefficients for maize were $24.4 \%, 26.2 \%, 22.3 \%$ and $17.8 \%$, respectively. NPKM and NPKS treatments had relatively low coefficients, indicating that adding manure or straw might have helped to maintain a stable crop yield. Overall, NPKM and NPKS treatments had the highest productions and lowest annual variations.

\subsection{Soil organic carbon dynamics}

The dynamics of SOC stored in the soil is determined by the SOC input and the decomposition rate of SOC (De Nobili et al., 2008). When the input and decomposition achieve balance, the SOC in the soil is in equilibrium. After the 23-year experiment, the SOC contents were significantly different among the treatments (Fig. 4). The SOC was $27.5 \mathrm{t} \mathrm{C} / \mathrm{hm}^{2}$ (Lv et al., 2016) in the 0-20 $\mathrm{cm}$ soil layer at the beginning of the study in 1990 and reached $53.35 \mathrm{t} \mathrm{C} / \mathrm{hm}^{2}$ under the NPKM treatment in 2012, which was the highest SOC among all the treatments. The SOC under NPK and NPKS treatments also showed significant increases, with values of 31.0 and $33.4 \mathrm{t} \mathrm{C} / \mathrm{hm}^{2}$, respectively, in 2012. Other treatments showed slight SOC decreases, with values of 25.6, 25.0, 23.6 and $27 \mathrm{t} \mathrm{C} / \mathrm{hm}^{2}$ for CK, PK, NK and NP treatments, respectively, in 2012.

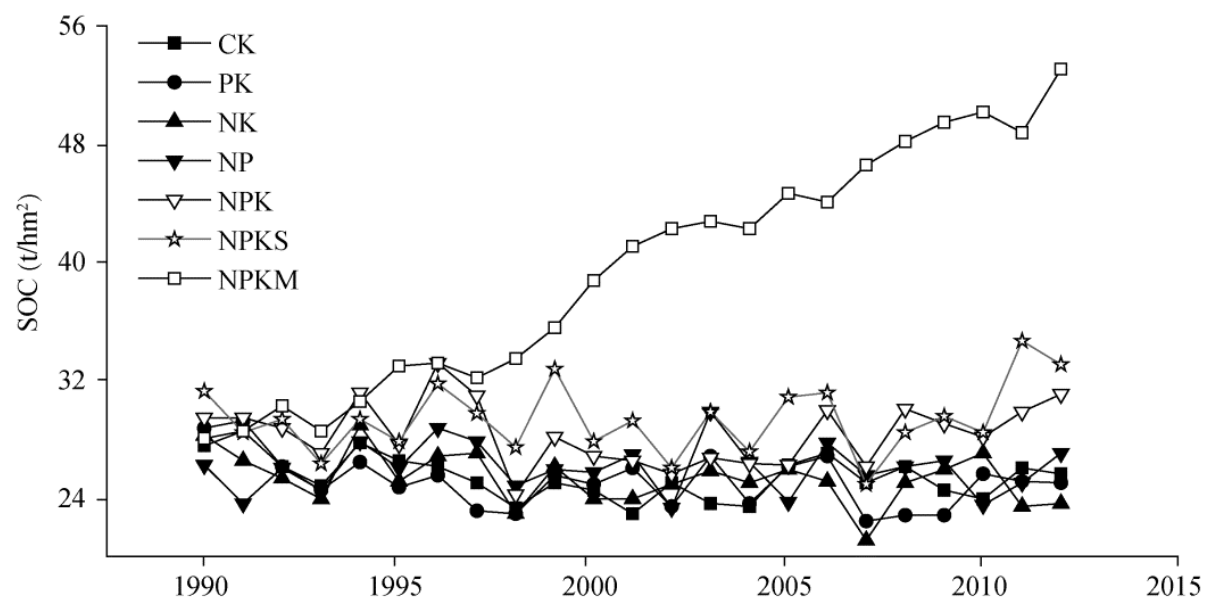

Fig. 4 Soil organic carbon (SOC) dynamics over the study period

\subsection{Carbon inputs and sequestration under different treatments}

Root/straw ratio is a vital parameter for estimating the $\mathrm{C}$ input. In this study, we used the observed results to get the root/straw ratios. The average ratios were $0.27,0.29,0.28,0.27,0.31$, 0.31 and 0.33 for the NPK, NPKM, NPKS, NP, NK, PK and CK treatments, respectively, in the 23-year experiment. Including the $\mathrm{C}$ input from straw and manure, the cumulative $\mathrm{C}$ inputs were 5.10, 7.36, 7.77, 11.15, and $10.57 \mathrm{t} \mathrm{C/ \textrm {hm } ^ { 2 }}$ in the CK, PK, NK and NPK treatments, respectively. The NPKS treatment had the highest cumulative $C$ input with a value of $73.95 \mathrm{t} \mathrm{C} / \mathrm{hm}^{2}$, followed by the NPKM treatment with a value of $70.91 \mathrm{t} \mathrm{C} / \mathrm{hm}^{2}$ (Table 3). The NPKM treatment had the highest root $\mathrm{C}$ input with a value of $12.67 \mathrm{t} \mathrm{C} / \mathrm{hm}^{2}$. NPKS and NPK treatments also had relatively high root $\mathrm{C}$ inputs. As evidenced for SOC sequestration, net annual SOC sequestrated was getting higher when manure was added along with NPK fertilizers, reaching a value of $1.2 \mathrm{t} \mathrm{C} /\left(\mathrm{hm}^{2} \cdot \mathrm{a}\right)$. The net annual SOC amounts sequestrated under NPKS and NPK treatments $(0.31$ and $0.30 \mathrm{t}$ $\mathrm{C} /\left(\mathrm{hm}^{2} \cdot \mathrm{a}\right)$, respectively) were significantly higher than that under NP treatment $\left(0.12 \mathrm{t} \mathrm{C} /\left(\mathrm{hm}^{2} \cdot \mathrm{a}\right)\right)$; and it presented slightly negative values of $-0.02,-0.07$ and $-0.09 \mathrm{t} \mathrm{C} /\left(\mathrm{hm}^{2} \cdot \mathrm{a}\right)$ for $\mathrm{CK}$, NK and PK treatments, respectively (Table 3 ). Unbalanced fertilizer had minimal effects on the SOC accumulation. These results indicated that the balanced applications of fertilizers, especially for manure amendment treatment (NPKM), can maintain both crop production and increase the soil C sequestration in this region. However, the unbalanced fertilization does not seem to be an acceptable practice considering the efficiency of SOC sequestration. 

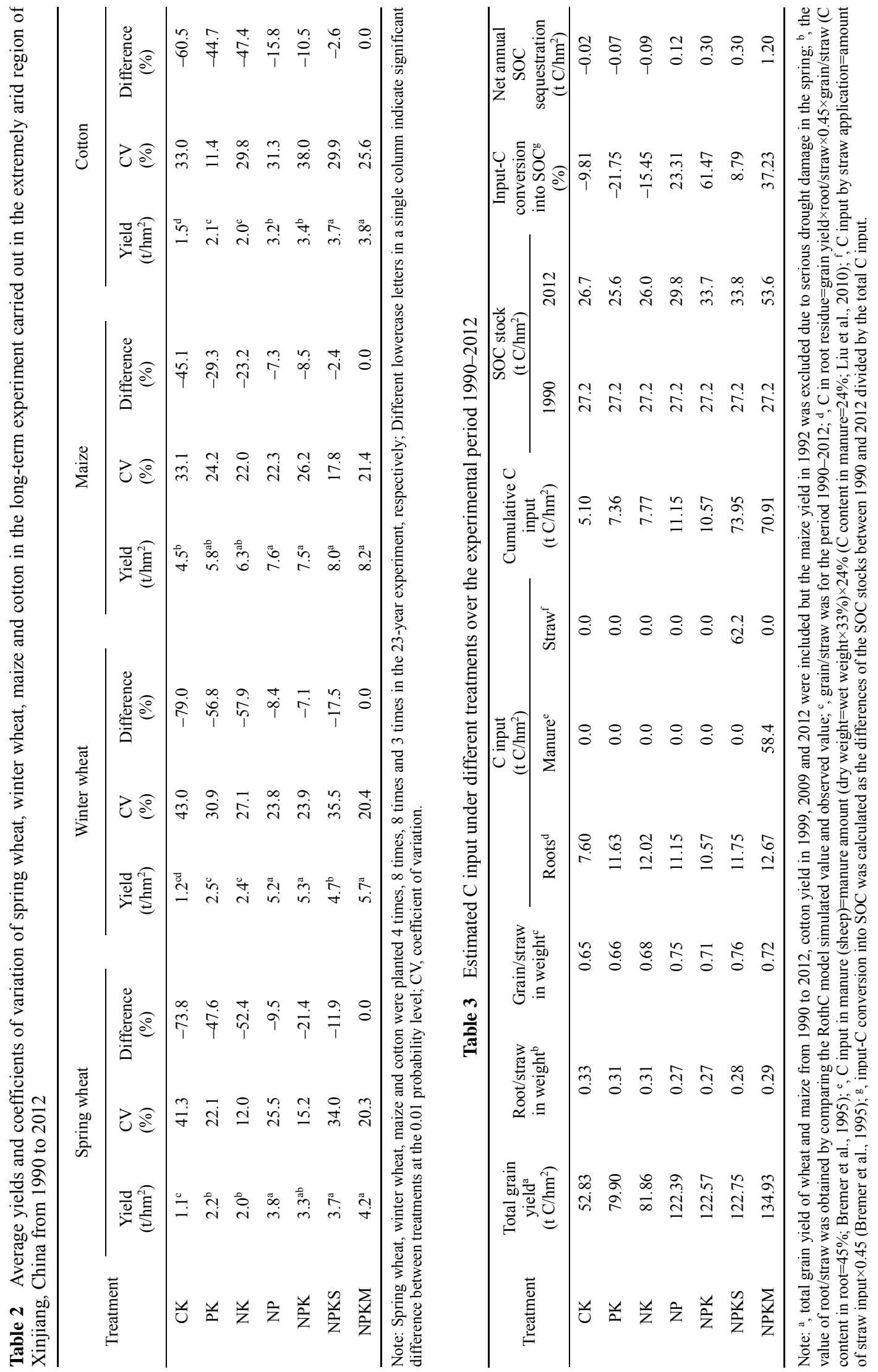


\section{Discussion}

\subsection{Fertilization and crop production}

Crop productivity in many areas of the world is largely constrained by limited precipitation and often by limited access to fertilizers (Rudrappa et al., 2006; Mazzoncini et al., 2011). However, the situation is different in extremely arid regions where water is supplied mainly through irrigation. The application of adequate amount of nutrients, especially N, P and K, or compost, can effectively improve the soil fertility in extremely arid regions except for chemical fertilizer (Wang et al., 2016). The SOC mineralization can also supply the necessary nutrients for crops. It is well known that the release of nutrients from organic manures is dependent on temperature (Ellert and Bettany, 1992; Zhang et al., 2011). The climate of arid areas is dry and hot with adequate sunshine, and the resulted high evaporation could cause a sharp and rapid SOC mineralization (Rong et al., 2012). In this study, NPKM treatment had the highest yield among all the treatments, being in contrast with that reported from the Huang-Huai-Hai Plain where NPK treatment had the highest yield (Cai and Qin, 2006; Huang et al., 2009). This was because of the more intense mineralization and soil permeability occurred in the NPKM treatment of this study, indicating that combined fertilizers and compost could help to maintain a better yield in the study area.

The yields under NPK and NP treatments did not show significant difference $(P>0.05)$, but they were significantly different from those under PK and NK $(P<0.05)$ treatments, suggesting that the oasis grey desert soil had an appropriate $\mathrm{K}$ content but deficient in $\mathrm{N}$ and $\mathrm{P}$ contents. The yield under NPKS treatment had no significant difference from that under NPK $(P>0.05)$ treatment, indicating that straw return had no marked effect on yield. The reason might be that a part of the inorganic $\mathrm{N}$ can be absorbed by the straw to meet the $\mathrm{N}$ demands of soil microorganism. Yield decreases were observed under NK, PK and CK treatments, which might be attributable to nutrient deficits of the plants (wheat, corn and maize) and also to the negative balance of macronutrients.

\subsection{SOC sequestration of different fertilizer treatments}

The SOC sequestration under different fertilizer treatments exhibited significant differences. Compared with other treatments $(P<0.01)$, SOC content increased markedly under NPKM treatment, indicating that the combination of fertilization and compost could not only increase yields but also increase SOC content. These results were generally similar to those found in the Loess Plateau and in the North China Plain (Yan and Gong, 2010; Guo et al., 2012). This probably was caused by easier and quicker mineralization occurred in the extremely arid area due to the high evaporation. The results showed that NPKM treatment displayed a relatively steep increasing trend with an increasing amount of application. The NPKS, NPK and NP treatments displayed rather gentle SOC increasing trends with an increasing amount of application. SOC under the unbalanced fertilizer treatments was slightly reduced after the 23 years.

In addition, we found that NPKM treatment had a higher root $\mathrm{C}$ input than other treatments. It meant that manure additions have contributed to the amount of roots, root exudates, stubble, and litter, despite a low root/straw ratio. However, the SOC level of NPKM treatment significantly increased after 23 years perhaps due to the low SOC background, implying that the manure amendment treatment had a greater potential for increasing SOC. For NPKS treatment, we found that there was a clear increasing trend of SOC with an increasing amount of application, however, the increasing trend was not as steep as that in the humid areas (Liu et al., 2005; Studdert et al., 2011), probably because the straw had a higher decomposition rate under the large temperature diurnal changes and the frequent wet-dry cycles in the arid irrigation conditions. However, other studies (Li et al., 2012; Lv et al., 2014) reported that NPKS treatment had a significantly higher $\mathrm{CO}_{2}$ emission than NPK treatment in the oasis cropland, probably meaning that NPKS treatment 
had a better soil respiration than NPK treatment. A better soil respiration could lead to an intensified SOC mineralization under NPKS treatment.

\section{Conclusions}

We conclude that applications of organic manure with inorganic fertilizers can deliver high and stable yields for spring wheat, winter wheat and maize in extremely arid areas. Balanced applications of inorganic NPK fertilizers enable farmers to maintain high yields and sustainable stable food production in this region, but soil carbon sequestration is limited under NPK treatment. Nevertheless, NPKM treatment not only increased the yields but also directly and indirectly contributed to carbon sequestration by adding manure and increasing crop residues. Our results suggest that the region has a large SOC sequestration potential, implying that food production and soil carbon sequestration can be simultaneously realized by combined application of inorganic and organic fertilizers (e.g., NPKM).

\section{Acknowledgements}

This work was funded by the National Basic Research Program of China (2014CB954200), the National Natural Science Foundation of China $(41425007,41005001)$ and the National Gray Desert Soil Fertility and Fertilizer Efficiency Monitoring Station of China.

\section{References}

Ai N, Wei T X, Zhu Q K, et al. 2017. Impacts of land disturbance and restoration on runoff production and sediment yield in the Chinese Loess Plateau. Journal of Arid Land, 9(1): 76-86.

Bao S D. 2000. Soil and Agricultural Chemistry Analysis ( $3^{\text {rd }}$ ed.). Beijing: China Agriculture Press, 98-103. (in Chinese)

Batjes N H. 1996. Total carbon and nitrogen in the soils of the world. European Journal of Soil Science, 47(2): 151-163.

Bremer E, Ellert B H, Janzen H H. 1995. Total and light-fraction carbon dynamics during four decades after cropping changes. Soil Science Society of America Journal, 59(5): 1398-1403.

Cai Z C, Qin S W. 2006. Dynamics of crop yields and soil organic carbon in a long-term fertilization experiment in the Huang-Huai-Hai Plain of China. Geoderma, 136(3-4): 708-715.

De Nobili M, Contin M, Mahieu N, et al. 2008. Assessment of chemical and biochemical stabilization of organic C in soils from the long-term experiments at Rothamsted (UK). Waste Management, 28(4): 723-733.

Ellert B H, Bettany J R. 1992. Temperature dependence of net nitrogen and sulfur mineralization. Soil Science Society of America Journal, 56(4): 1133-1141.

Gong Z T, Zhang G L, Chen Z C, et al. 2007. Pedogenesis and Soil Taxonomy. Beijing: Science Press, 672. (in Chinese)

Guo S L, Wu J S, Coleman K, et al. 2012. Soil organic carbon dynamics in a dryland cereal cropping system of the Loess Plateau under long-term nitrogen fertilizer applications. Plant and Soil, 353(1-2): 321-332.

Huang Q R, Hu F, Huang S, et al. 2009. Effect of long-term fertilization on organic carbon and nitrogen in a subtropical paddy soil. Pedosphere, 19(6): 727-734.

Kismányoky T, Tóth Z. 2013. Effect of mineral and organic fertilization on soil organic carbon content as well as on grain production of cereals in the IOSDV (ILTE) long-term field experiment, Keszthely, Hungary. Archives of Agronomy and Soil Science, 59(8): 1121-1131.

Li C S, Frolking S, Xiao X M, et al. 2005. Modeling impacts of farming management alternatives on $\mathrm{CO}_{2}, \mathrm{CH}_{4}$, and $\mathrm{N}_{2} \mathrm{O}$ emissions: a case study for water management of rice agriculture of China. Global Biogeochemical Cycles, 19(3): GB3010.

Li Z G, Zhang R H, Wang X J, et al. 2012. Growing season carbon dioxide exchange in flooded non-mulching and non-flooded mulching cotton. PLoS ONE, 7(11): e50760.

Liu H, Tong X G, Ma X W, et al. 2010. Content and evolution characteristics of organic carbon associated with particle-size fractions of grey desert soil under long-term fertilization. Chinese Journal of Applied Ecology, 21(1): 84-90. (in Chinese)

Liu X J, Ai Y W, Zhang F S, et al. 2005. Crop production, nitrogen recovery and water use efficiency in rice-wheat rotation as affected by non-flooded mulching cultivation (NFMC). Nutrient Cycling in Agroecosystems, 71(3): $289-299$.

Luo C, Yang D, Peng Z C, et al. 2006. The climatic and environmental records in the sediment of the Luobei billabong in the district of Lop-Nur, Xinjiang in recent $30 \mathrm{ka}$. Geochimica et Cosmochimica Acta, 70(18): A376. 
Lv J L, Liu X J, Liu H, et al. 2014. Greenhouse gas intensity and net annual global warming potential of cotton cropping systems in an extremely arid region. Nutrient Cycling in Agroecosystems, 98(1): 15-26.

Lv J L, Liu X J, Liu H, et al. 2016. Highly arid oasis yield, soil mineral N accumulation and $\mathrm{N}$ balance in a wheat-cotton rotation with drip irrigation and mulching film management. PLoS ONE, 11(10): e0165404, 1-17.

Manna M C, Swarup A, Wanjari R H, et al. 2007. Long-term fertilization, manure and liming effects on soil organic matter and crop yields. Soil and Tillage Research, 94(2): 397-409.

Mazzoncini M, Sapkota T B, Bàrberi P, et al. 2011. Long-term effect of tillage, nitrogen fertilization and cover crops on soil organic carbon and total nitrogen content. Soil and Tillage Research, 114(2): 165-174.

Min J, Zhao X, Shi W M, et al. 2011. Nitrogen balance and loss in a greenhouse vegetable system in southeastern China. Pedosphere, 21(4): 464-472.

Niu L A, Hao J M, Zhang B Z, et al. 2011. Influences of long-term fertilizer and tillage management on soil fertility of the north China plain. Pedosphere, 21(6): 813-820.

Rong J R, Li C H, Wang Y G, et al. 2012. Effect of long-term fertilization on soil organic carbon and soil inorganic carbon in oasis cropland. Arid Zone Research, 29(4): 592-597. (in Chinese)

Rudrappa L, Purakayastha T J, Singh D, et al. 2006. Long-term manuring and fertilization effects on soil organic carbon pools in a Typic Haplustept of semi-arid sub-tropical India. Soil and Tillage Research, 88(1-2): 180-192.

Studdert G A, Monterubbianesi M G, Domínguez G F. 2011. Use of RothC to simulate changes of organic carbon stock in the arable layer of a Mollisol of the southeastern Pampas under continuous cropping. Soil and Tillage Research, 117: 191-200.

Wang J C. 2001. Crop yields and nutrient dynamics impacted by different mulching styles in upland rice/wheat rotation systems. PhD Dissertation. Beijing: China Agricultural University, 56-58. (in Chinese)

Wang W, Chen W C, Wang K R, et al. 2011. Effects of long-term fertilization on the distribution of carbon, nitrogen and phosphorus in water-stable aggregates in paddy soil. Agricultural Sciences in China, 10(12): 1932-1940.

Wang X, Lv J L, Liu H. 2016. Potassium balance and use efficiency in grey desert soil under continuous wheat-maize-cotton crop rotation system. Acta Pedologica Sinica, 53(1):210-220.

Xu M, Liu H. 2006. Chinese Fertility Evolution. Beijing: China Agricultural Science and Technology Press, 218-276. (in Chinese)

Yan X Y, Gong W. 2010. The role of chemical and organic fertilizers on yield, yield variability and carbon sequestration — results of a 19-year experiment. Plant and Soil, 331(1-2): 471-480.

Yang X Y, Li P R, Zhang S L, et al. 2011. Long-term-fertilization effects on soil organic carbon, physical properties, and wheat yield of a loess soil. Journal of Plant Nutrition and Soil Science, 174(5): 775-784.

Yang Y H, Chen Y N, Li W H, et al. 2012. Climatic change of inland river basin in an arid area: a case study in northern Xinjiang, China. Theoretical and Applied Climatology, 107(1-2): 143-154.

Zhang H M, Yang X Y, He X H, et al. 2011. Effect of long-term potassium fertilization on crop yield and potassium efficiency and balance under wheat-maize rotation in China. Pedosphere, 21(2): 154-163. 